Est Ag 52 (2017) 123-143

\title{
El significado del término euaggelion en los comienzos del cristianismo
}

\section{SANTIAGO GuiJarro OpORTO}

RESUMEN: El término "evangelio" (griego: euaggelion) se ha estudiado en el marco de un modelo diacrónico que ha impedido percibir claramente los diversos significados que los primeros seguidores de Jesús dieron a esta palabra. A pesar de ello, los primeros escritos cristianos dan testimonio de que estos diversos sentidos coexistieron hasta mediados del siglo segundo. El presente estudio identifica dos trayectorias presentes en dichos escritos y propone una explicación de los significados que la palabra "evangelio" adquirió en ellos, observando que estos dos significados surgieron en dos contextos diversos (la tierra de Israel y la Diáspora), que determinaron la comprensión de esta palabra clave del sociolecto cristiano.

Palabras ClAve: Evangelio, orígenes del cristianismo, contexto social, sociolecto cristiano.

ABSTRACT: The study of the term "Gospel" (Greek: euaggelion) has been conducted in the framework of a diachronic model that has prevented to perceive clearly the various meanings that the first followers of Jesus gave to this word. However, the early Christian writings testify that these different meanings coexisted until the mid-second century. This study identifies two trajectories reflected in these writings and proposes an explanation of the meanings that the word "Gospel" acquired in them noting that they arose in a different context (the Land of Israel and the Diaspora), which determined the understanding of this keyword of the Christian sociolect.

KEywords: Gospel, Christian Origins, Social Context, Christian Sociolect. 


\section{UN TÉRMINO IDENTITARIO}

"Evangelio" es, probablemente, una de las palabras más distintivas y características del vocabulario cristiano ${ }^{1}$. Desde los inicios del cristianismo hasta nuestros días se utiliza corrientemente para designar la buena noticia que constituye el núcleo del mensaje de Jesús. Ahora bien, la familiaridad que genera este uso habitual puede ocultar los matices que esta palabra tenía para los primeros cristianos. En el contexto en que ellos vivían, la palabra "evangelio" no se usaba con tanta frecuencia como hoy, y además tenía un significado diferente al que tiene para nosotros. Fueron ellos quienes, con el uso frecuente, hicieron de esta palabra un término clave del lenguaje cristiano.

Ciertamente, el término existía y era utilizado tanto en contexto judío como en el mundo helenístico. En el contexto judío existía el verbo biser (anunciar bunas noticias) que Septuaginta, la traducción griega de las Escrituras de Israel, había traducido por euaggelizesthai, sobre todo en algunos pasajes del profeta Isaías que hablan de la acción liberadora de Dios con respecto a su pueblo (Is 40, 9; 52, 7; 60, 6; 61, 1). En el mundo helenístico, por el contrario, el término se empleaba en plural (euaggelia), y se usaba sobre todo en el contexto de la propaganda oficial, que desde tiempos de Augusto estaba estrechamente vinculada al culto al emperador ${ }^{2}$.

Los primeros cristianos tomaron prestado este término conocido, pero lo redefinieron completamente dándole un nuevo sentido que no se encontraba ni en las escrituras judías ni en la teología imperial. Con respecto a las escrituras judías, insistieron en el hecho de que en Jesús se había cumplido lo anunciado por Isaías. En relación a la propaganda imperial, resaltaron que para ellos el evangelio no era la buena noticia de la iniciativa divina manifestada en el dominio (imperium) del césar, sino

1 Este artículo es una versión revisada del trabajo que fue publicado originalmente en la Revue Théologique de Louvain 45 (2014) 481-501.

${ }^{2}$ El trasfondo del uso no cristiano del término fue ya estudiado por FrIEDRICH, Gerhard, "Euaggelizomai, 'evangelio"”, en KiTTEL, Gerhard (ed.), Theologisches Wörterbuch zum Neuen Testament, Band II, Kohlhammer, Stuttgart 1935, 719-722. Sus observaciones, sin embargo, han sido precisadas en trabajos más recientes como el de STANTON, Graham, Jesús y el evangelio, Desclee de Brouwer, Bilbao 2004, 53-64, que subraya la importancia de su uso en la literatura judía de lengua griega (Filón, Legat. 99; 231; Flavio Josefo, Ant. 18, 261-309), y sobre todo en la inscripción hallada en Priene y otras cuatro ciudades. Sobre esta inscripción y su relación con el uso cristiano del término, véase: Evans, Craig, "Mark's Incipit and the Priene Calendar Inscription: From Jewish Gospel to GrecoRoman Gospel”, en Journal of Graeco-Roman Christianity and Judaism 1 (2000) 67-81. 
la intervención definitiva de Dios en Jesús, el Mesías³ ${ }^{3}$ De este modo, dieron un sentido nuevo a este término ya conocido y lo incorporaron a su "idiolecto", es decir, al lenguaje que compartían y que reforzaba su identidad común. El término "evangelio" se convirtió así para ellos en un término identitario 4 .

Conscientes de la importancia de esta palabra, tanto los historiadores del cristianismo como los estudiosos de la Biblia han querido comprender por qué los primeros cristianos la incorporaron a su vocabulario particular y cuál era el sentido que tenía para ellos. En los últimos años, particularmente, han intentado responder a tres preguntas: ¿Cuál era el sentido que los creyentes en Jesús dieron a este término? ¿Utilizó Jesús mismo este término para designar su mensaje? ¿Cómo se relacionan los diferentes sentidos del término "evangelio" que encontramos en los primeros escritos cristianos?

La primera pregunta tiene relación con el hecho de que los más antiguos relatos sobre Jesús recibieran a mediados del siglo II el nombre de "evangelios". El problema consiste en saber si esta palabra tenía ya tal sentido cuando Marcos la utilizó para introducir su relato sobre Jesús (Mc 1,1). La investigación ha aclarado que los primeros discípulos de Jesús utilizaron esta palabra para referirse al mensaje oral que habían recibido y que transmitían (1Cor 15,1-5). Solamente después de la composición de los evangelios, muy probablemente hacia mediados del siglo II, el sustantivo "evangelio" comenzó a utilizarse para designar los evangelios escritos 5 . Fue entonces cuando empezó a ponerse títulos a las diferentes copias que se hacían de los distintos relatos para distinguirlos, y

3 Tal vez por esta razón los primeros cristianos utilizaron la palabra solo en singular hasta mediados del siglo II, cuando comenzó a designar los evangelios escritos; véase: STANTON, Jesús y el evangelio, 51.

${ }^{4}$ La sociolingüística designa este lenguaje compartido por los miembros de un mismo grupo con el término "sociolecto", subrayando que el vocabulario característico del mismo procede del lenguaje común y que, por tanto, puede ser comprendido por los de fuera, aunque no en el sentido particular que tiene para los miembros del grupo. STANTON, Jesús y el evangelio, 87-92, menciona otros términos que siguieron un proceso similar: logos, charis, etc.

${ }^{5}$ La tesis de Köster, Helmut, Ancient Christian Gospels, Trinity Press, Harrisburg 1990, 35-37, según la cual los evangelios habrían recibido este nombre en el contexto de la polémica provocada por Marción al identificar el "evangelio" con el relato de Lucas, ha sido revisada por STANTON, Jesús y el evangelio, 92-100, quien atribuye este cambio a Mateo, y por KelHofer, James, "'How Soon a Book' Revisited: Euaggelion as a Reference to 'Gospel' Materials in the First Half of the Second Century", en Zeitschrift für die neutestamentliche Wissenschaft 95 (2004) 1-34, que la sitúa después de la composición de Mateo, pero antes de la Didajé y de la Segunda carta de Clemente. 
cuando encontramos en Justino el primer uso del término "evangelios" (en plural), para designar las "memorias de los apóstoles"6.

La segunda pregunta evoca una cuestión más amplia relacionada con el sentido cristiano del término. El punto de partida, en este caso, es el empleo tan frecuente que hace Pablo en sus cartas del sustantivo "evangelio" y del verbo "evangelizar". Este uso es muy llamativo, sobre todo si lo comparamos con el empleo mucho más modesto que hacen los evangelios. Tal contraste, y el hecho de que la mayoría de las menciones de los evangelios sean consideradas como redaccionales, han hecho pensar que Pablo y sus comunidades fueron los primeros en utilizar esta palabra en un sentido nuevo. Sin embargo, un estudio más detallado de la tradición evangélica, particularmente del uso que Jesús hizo de algunos pasajes de Isaías, ha convencido a la mayoría de los estudiosos de que Jesús utilizó muy probablemente el verbo "evangelizar" en su predicación, y, por tanto, que el uso cristiano del término se remonta, en última instancia, hasta él7.

Finalmente, la tercera pregunta surge al constatar que el sustantivo "evangelio", al igual que el verbo "evangelizar", tienen a menudo sentidos diferentes. En la mayor parte de los casos, el contenido del "evangelio" es Jesús, sobre todo su muerte y resurrección. El "evangelio", en este caso, es la buena noticia sobre Jesús. Pero en otros casos, menos numerosos ciertamente, pero no menos importantes, el contenido del "evangelio" es el mensaje de Jesús. En estos otros textos, el "evangelio" no es la buena noticia sobre Jesús, sino la buena noticia de Jesús, es decir, la buena noticia que Jesús anuncia. En el Nuevo Testamento, la primera acepción se encuentra, sobre todo, en las cartas de Pablo, pero también en el Evangelio según Marcos (el sustantivo) y en el Evangelio según Lucas (el verbo). La segunda acepción se encuentra, sobre todo, en el Evangelio según Mateo, pero también en el Evangelio según Marcos (el sustantivo, en ambos casos) y en el Evangelio según Lucas (el verbo).

Los exegetas han intentado relacionar estas dos acepciones del término "evangelio" con ayuda de un modelo diacrónico que presupone una evolución. Han intentado explicar así, por ejemplo, cómo se pasó del

\footnotetext{
6 Sobre los títulos de los evangelios, véase: Hengel, Martin, "The Titles of the Gospels and the Gospel of Mark", en IDEM, Studies in the Gospel of Mark, Philadelphia, Fortress Press, 1985, 64-84. Sobre Justino: Köster, Ancient Christian Gospels, 40-43.

${ }^{7}$ FRIEDRICH, Gerhard, "Euaggelizomai, euaggelion", 715-16 y 725-726, se planteó ya esta cuestión. Sin embargo, ha sido STANTON, Jesús y el evangelio, 35-45, quien ha presentado la argumentación más convincente mostrando que Jesús entendió probablemente su propia misión a partir de Is 61,1 .
} 
anuncio de la buena noticia de Jesús, es decir, del evangelio anunciado por Jesús, a la buena noticia sobre Jesús, es decir, al evangelio anunciado por sus discípulos después de su resurrección ${ }^{8}$.

Ahora bien, esta forma de explicar los diversos sentidos que la palabra "evangelio" tenía para los primeros cristianos no toma en cuenta los elementos contextuales que pudieron determinar tal diversidad. Por ello, en este trabajo quisiera considerar algunos factores de tipo regional y cultural que pudieron afectar a la definición de estos dos términos en los orígenes del cristianismo. De esta forma espero poner de manifiesto la riqueza que supone el uso de estas palabras, mostrando que pudieron haber tenido diversos sentidos en la misma época, y que el diálogo con los diversos contextos culturales pudo haber afectado de manera decisiva a la definición de estos términos identitarios.

La comparación entre el Evangelio según Mateo y el Evangelio según Marcos puede ser un buen punto de partida para esta investigación por diversas razones. En primer lugar, porque son los dos únicos evangelios que utilizan el sustantivo "evangelio". Pero, ante todo, porque es en ellos donde encontramos el contraste más evidente entre los dos sentidos ya mencionados. En todo caso, para comprender adecuadamente el origen y el sentido de este término será necesario ampliar la búsqueda teniendo en cuenta también el uso que hacen de él otros textos canónicos y no canónicos hasta mediados del siglo II, que fue cuando comenzó a ser utilizado para designar los "libros sobre Jesús" 9 .

\section{II. “Evangelio" en los relatos de Marcos y de Mateo}

En su conocida monografía sobre la redacción del Evangelio según Marcos, Willi Marxen compara minuciosamente el uso que se hace del término "evangelio" en los Evangelios según Marcos y según Mateo. Su análisis, explícitamente diacrónico, trata de subrayar dos hechos. En pri-

8 Burrows, Millar, "The Origin of the Term 'Gospel”", en Journal of Biblical Literature 44 (1925) 32-33 planteó ya esta cuestión al observar la diferencia entre el uso que Jesús hace de este término en los evangelios y el que hace Pablo en sus cartas. Desde el punto de vista redaccional, MARXEN, Willi, El evangelista Marcos. Estudio sobre la historia de la redacción del evangelio, Sígueme, Salamanca 1981, 131-134, observó la diferencia entre la perspectiva de Marcos y la de Mateo. Pero tanto Burrows como Marxen intentaron explicar estas diferencias en un marco de comprensión diacrónico.

9 Tomo esta expresión genérica para designar los diversos tipos de evangelios de Hurtado, Larry, Señor Jesucristo. La devoción a Jesús en el cristianismo primitivo, Sígueme, Salamanca 2008, 301-398. 
mer lugar, que fue Marcos quien introdujo este término en su relato sobre Jesús y, en consecuencia, que dicho término no proviene de la tradición. Y en segundo lugar, que las modificaciones introducidas por Mateo se explican por la nueva situación que vivían sus destinatarios ${ }^{10}$. El análisis de Marxen ha influido mucho en los estudios posteriores, los cuales, al aceptar este enfoque diacrónico, consideran secundaria la comprensión mateana del término "evangelio".

En este estudio me propongo adoptar un enfoque diferente. Sugiero que para comprender cómo entienden cada uno de los dos relatos el término evangelio es necesario leerlos como relatos independientes. Solo en un segundo momento será útil incorporar el análisis diacrónico para explicar los motivos de algunas diferencias. Este enfoque nos llevará inevitablemente a preguntarnos por qué estos dos evangelios dan a dicho término un sentido tan diferente.

\section{1. “Evangelio" en el relato de Marcos}

En el relato de Marcos, el término "evangelio" ocupa un lugar importante. El narrador lo usa en el incipit de su obra con una solemnidad remarcable. En esta primera mención (Mc 1,1), "evangelio" designa la buena noticia sobre Jesús que va a ser contada: una buena noticia cuyo comienzo (Mc 1,4-15) corresponde, según el narrador, a lo que había sido anunciado por el profeta Isaías (Mc 1,2-3) ${ }^{11}$. Esta comprensión del "evangelio" representa el punto de vista que el narrador propone como clave de lectura del relato.

La segunda vez que aparece el término es también el narrador quien lo enuncia. Pero en esta segunda mención "evangelio" parece tener otro sentido. No se trata ya del "evangelio de Jesús", sino del "evangelio de Dios" que Jesús anuncia. El narrador distingue bien estas dos acepciones del término "evangelio". El argumento de su relato, es decir, de la historia que va a contar es "el evangelio de Jesús". El evangelio de Dios anunciado por Jesús forma parte de esta historia y, en consecuencia, pertenece al "evangelio de Jesús". Según el narrador, por tanto, el "evangelio de

10 MARXEN, El evangelista Marcos, 111-143.

11 La cita, de hecho, incorpora frases que proceden de tres textos diferentes; véase: Marcus, Joel, The Way of the Lord. Christological Exegesis of the Old Testament in the Gospel of Mark, T. \& T. Clark, Edinburg 1992, 12-22. Por otro lado, GuELICH, Robert, "The Beginning of the Gospel, Mark 1.1-15", en Biblical Review 27 (1982) 5-15, 6-8, ha mostrado de forma convincente que la cita de Mc 1,2-3 está vinculada a Mc 1,1. 
Jesús" incluye la buena noticia de la venida del reinado de Dios anunciado por Jesús, pero va más allá de este anuncio, porque su contenido es Jesús mismo12.

Después de estas dos menciones iniciales, el término "evangelio" aparece en el relato siempre en boca de Jesús y siempre sin modificadores. Los lectores conocen ya su sentido y, por esta razón, Jesús puede hablar de "el evangelio" sin más. Esta forma de hablar muestra que el sentido de la palabra en el relato de Marcos es el que el narrador ha revelado al lector al comienzo de la narración. De hecho, en los cinco casos en los que Jesús habla del evangelio, esta palabra está siempre estrechamente relacionada con él, confirmando así que se trata del "evangelio de Jesús".

Solamente en el primero de estos casos la proximidad de la referencia al "evangelio de Dios" (Mc 1,14) podría sugerir que la invitación de Jesús a "creer en el evangelio" (Mc 1,15) es una invitación a creer en la venida inminente del reinado de Dios. Sin embargo, conviene observar que Jesús habla de "el evangelio" en sentido absoluto, y no de la buena noticia que acaba de proclamar, la cual también forma parte de "el evangelio (de Jesús)".

Las otras cuatro menciones de "el evangelio" confirman esta interpretación. Dos de ellas, formuladas con las mismas palabras, se encuentran en las instrucciones que Jesús dirige a sus discípulos en el contexto de los anuncios de la pasión (Mc 8,35; 10,29). Ambas aluden a los sufrimientos y los sacrificios que tendrán que soportar por su causa y por el evangelio, identificando así "el evangelio" con Jesús.

Las dos últimas se encuentran al final del relato y se refieren al anuncio del evangelio. En la primera de ellas (Mc 13,10), este anuncio está relacionado con la comparecencia de los discípulos ante gobernadores y reyes "a causa de mín", vinculando así de nuevo el evangelio con Jesús. En la segunda, situada en la escena de la unción en Betania (Mc 14,9), que es la clave hermenéutica de relato de la pasión, Jesús asegura a sus discípulos que el gesto realizado por la mujer será recordado allí donde se anuncie "el evangelio". Ahora bien, el hecho de ungir a Jesús en la cabeza anticipando su sepultura revela que ella ha comprendido mejor que todos los demás actores del relato el sentido del mesianismo

12 Focant, Camille, L'Évangile selon Marc (=Commentaire Biblique: Nouveau Testament 2), Du Cerf, Paris 2004, 54, observa bien esta diferencia. Habría que añadir que, al hacer esta distinción, el narrador revela una cierta conciencia histórica, pues sabe que Jesús había anunciado la venida del reinado de Dios y que había comprendido este anuncio como una buena noticia (véase: Mt 11,5; par. Lc 7,27). 
de Jesús. Por esta razón su gesto será recordado allí donde se anuncie el evangelio ${ }^{13}$.

En el relato de Marcos, por tanto, "el evangelio" es, ante todo, la buena noticia sobre Jesús. Esta buena noticia se expresa en la historia que cuenta: una historia cuyo comienzo corresponde a lo anunciado por el profeta Isaías, y cuya finalidad es revelar el mesianismo de Jesús. Para él, a fin de cuentas, el evangelio es Jesús.

\section{2. "Evangelio" en el relato de Mateo}

En el Evangelio según Mateo, el término "evangelio" tiene un significado muy diferente. A diferencia de Marcos, Mateo no entiende su relato como un "evangelio", ni siquiera su comienzo, al que da el título de "libro del nacimiento", o genealogía (Mt 1,1). Para él, el término "evangelio" define un aspecto muy específico de la actividad de Jesús que sus discípulos deberán continuar realizando hasta su segunda venida.

La palabra "evangelio" aparece, de hecho, por primera vez en un sumario de la actividad de Jesús. Esta actividad se describe con tres verbos: él enseñaba en sus sinagogas, anunciaba el evangelio del reino y curaba las enfermedades (Mt 4,23). Al igual que en el relato de Marcos, es el narrador quien introduce la palabra. Y no solo en esta primera mención, sino también en la segunda, que se encuentra igualmente en un sumario (Mt 9,35). Ambos sumarios tienen la función de orientar la lectura de la primera parte del relato mateano. No en vano están situados al comienzo y al final de la actividad inicial de Jesús, que Mateo ha ordenado cuidadosamente, colocando primero el anuncio de Jesús sobre la venida del reino (Mt 4,17), y luego su enseñanza (Mt 5-7) y sus curaciones (Mt 9-9).

Como ya hemos visto en el relato de Marcos, la voz del narrador expresa el punto de vista normativo desde el que debe leerse el relato. Pero en este caso, el punto de vista que el narrador propone es muy diferente. En el Evangelio de Mateo, en efecto, ya no se trata ni del "evangelio de Jesús", ni del "evangelio de Dios", sino del "evangelio del reino", cuyo anuncio es, para Mateo, solo una parte de la actividad de Jesús. De

13 Marcos ha otorgado a este episodio una gran importancia. El gesto de la mujer, que unge a Jesús en la cabeza, como hacían los antiguos profetas con los reyes, expresa el sentido del mesianismo de Jesús, pues esta unción se hace "para la sepultura"; véase: GuIJARro, Santiago - RodríQuez, Ana, "La unción "mesiánica”de Jesús (Mc 14,3-9)”, en Salmanticensis 60 (2013) 43-66. 
esta forma, el narrador orienta a los lectores sobre el sentido del término "evangelio" para que lo entiendan adecuadamente cuando lo encuentren de nuevo en su relato.

De hecho, lo encontrarán otras dos veces, ambas al final de su narración, exactamente en el mismo lugar en que se encuentran las dos últimas referencias de Marcos. La primera de ellas, situada en el discurso escatológico, habla del anuncio del evangelio al mundo entero como testimonio para todas las naciones (Mt 24,14). Mateo precisa que el contenido de este anuncio será "el evangelio del reino", es decir, el evangelio del que el narrador ha hablado ya. Pero la terminología utilizada para describir a los destinatarios ("las naciones", "los paganos") evoca anticipadamente la escena del mandato misionero postpascual, cuando los discípulos serán enviados a "todas las naciones" (Mt 28,19). El evangelio del que Jesús habla aquí es el que sus discípulos anunciarán después de su muerte y resurrección. Este anuncio no será diferente al que proclamaron Juan Bautista, Jesús o los Doce (Mt 3,1-2; 4,17; 10,7)14. Al igual que ocurrió durante el ministerio de Jesús, la respuesta a este anuncio será el primer paso para hacerse discípulo suyo (Mt 4, 17-22; 28,19) y poder así recibir su enseñanza (Mt 5,1-2;28,20) $)^{15}$.

La segunda y última mención de la palabra "evangelio" se encuentra en la escena de la unción de Betania (Mt 26,13). También aquí hay una alusión anticipada al mandato misionero, porque en ella se habla del momento en que el evangelio será anunciado en el mundo entero. Este

14 Mateo, como es sabido, subraya la continuidad entre estos tres anuncios haciendo que el mensaje anunciado por Juan, por Jesús y por los Doce sea exactamente el mismo.

15 Según MarXen, El evangelista Marcos, 134, para Mateo el contenido del evangelio es la enseñanza de Jesús. DAvies, William - Allison, Dale, The Gospel according to Saint Matthew (=The International Critical Commentary 1/1), T. \& T. Clark, Edinburgh 1988, 247-250, piensan también que en el relato de Mateo es muy difícil distinguir entre la predicación de Jesús y su enseñanza. Por su parte, Luz, Ulrich, El evangelio según Mateo (Mt 1-7), Sígueme, Salamanca ${ }^{3}$ 2010, 301-305, confirma esta interpretación con argumentos convincentes. Según él, el reinado de Dios, que es el contenido de la proclamación de Jesús, es un tema recurrente en su enseñanza, mientras que en el envío postpascual, al que aluden Mt 24,14 y 26,13, Jesús habla de enseñanza y no de anuncio. Sin embargo, en mi opinión, habría que tomar en serio el hecho de que el narrador distinga claramente los tres tipos de acciones que caracterizan la actividad de Jesús, pues es en ese contexto donde él habla del "evangelio". Las dos primeras menciones de este término pueden y deben ser comprendidas del mismo modo: como el contenido del anuncio de Jesús. De hecho, la alusión proléptica al envío misionero postpascual confirma esta interpretación. En dicho envío, en efecto, el verbo matheteuo (hacer discípulos) precede al verbo didasko (enseñar), de la misma forma que el anuncio de Jesús y la vocación de los primeros discípulos preceden a su enseñanza en el relato de Mateo (Mt 4,17-20; 5,1-7,28). 
evangelio es aquel del que el narrador y Jesús han hablado ya, y por eso Mateo se refiere a él como "este evangelio".

Así pues, en el Evangelio según Mateo, el término "evangelio" designa la buena noticia del reino anunciada por Jesús. Pero este anuncio es solo una parte de su actividad, que sus discípulos deberán continuar después de su muerte. Dicho de otra forma, el evangelio no es para Mateo la buena noticia sobre Jesús, sino la buena noticia del reino anunciada por él, es decir, la buena noticia de Jesús.

\section{Dos formas diferentes de entender el "evangelio"}

Un análisis sincrónico del término "evangelio" en los relatos de Marcos y de Mateo pone de manifiesto, como acabamos de ver, que ambos dan a esta palabra un sentido muy diferente. En un estudio diacrónico, esta diferencia no se aprecia con tanta claridad, porque el principal objetivo de este tipo de estudio es explicar las modificaciones que cada uno de los evangelistas introdujo sobre la tradición ${ }^{16}$. Los análisis que adoptan esta perspectiva se centran en explicar por qué Mateo ha suprimido cinco de las siete referencias de Marcos (Mc 1,1. 14. 15; 8,35; 10,29); por qué ha modificado sustancialmente otras dos (Mc 13,10 par. Mt 24,14; Mc 14,9 par. Mt 26,13); o por qué ha añadido dicho término en dos pasajes propios (Mt 4,23; 9,35).

A partir de este análisis se llega a la conclusión de que tales cambios se deben a que Mateo tenía una comprensión peculiar del evangelio, o a que en tiempos de Mateo esta palabra significaba algo diferente ${ }^{17}$. En todo caso, se considera que los cambios introducidos por Mateo suponen una evolución, una novedad con respecto a Marcos, y que, por tanto, reflejan las preocupaciones de una época posterior. Por esta razón, cuando se estudia desde esta perspectiva, la visión de Mateo apenas tiene interés para identificar el sentido originario del término evangelio.

16 MarXen, El evangelista Marcos, 134, reconoce que está básicamente de acuerdo con esta afirmación de Dibelius: "El anuncio de salvación se denomina 'evangelio' y, en este sentido, los cristianos no distinguen entre la predicación de Jesús y la predicación sobre Jesús" (Dibelius, Martin, La historia de las formas evangélicas, Edicep, Valencia 1984, 252).

17 A la primera conclusión llega Köster, Ancient Christian Gospels, 12: "The very distinctive understanding of the 'gospel' in Matthew may be the reason for his omission of the term in many of the Markan passages". La segunda, resume el resultado del análisis de MARXeN, Willi, El evangelista Marcos: 'Se puede sospechar que en su tiempo 'evangelio' significaba algo distinto de lo que por 'evangelio' entendería Marcos" (134). 
El análisis redaccional, por su misma naturaleza, utiliza un esquema de comprensión cronológico que se fija ante todo en la evolución. Sin embargo, si además de esta coordenada temporal (diacrónica), se tiene en cuenta la coordenada espacial (sincrónica) y se considera la posibilidad de que los primeros discípulos de Jesús entendieran esta palabra de forma diversa en los diversos contextos culturales en que vivieron, entonces las diferencias entre ellos se pueden explicar de otra forma.

\section{III. "Evangelio" EN PERSPECTIVA REgIONAL}

La tesis de este estudio es que la diferencia que hemos observado en la concepción que Mateo y Marcos tienen del término "evangelio" se explica, en parte, por la vinculación de ambos relatos a dos contextos vitales diferentes. Para validar esta afirmación es necesario mostrar, en primer lugar, que la comprensión que cada uno de ellos tiene del "evangelio" era compartida por otros grupos de discípulos de Jesús, lo cual implica mostrar que ambas formas de entender el término "evangelio" se hallan presentes en otros escritos protocristianos.

La concepción marquiana del evangelio es la que aparece más frecuentemente en los textos han llegado hasta nosotros. Estos textos, que tuvieron una gran difusión y ejercieron un notable influjo, entienden el "evangelio" como la buena noticia sobre Jesús. Los más importantes datan de periodos sucesivos, lo cual revela que esta forma de entender el evangelio tuvo una notable continuidad. Estos textos, en efecto, describen una trayectoria que comienza con las cartas de Pablo y continúa con las cartas deuteropaulinas y las cartas de Ignacio de Antioquía.

En el corpus paulino tanto el sustantivo "evangelio", como el verbo "evangelizar", aparecen con llamativa frecuencia. Excepto en las contadas ocasiones en las que se refiere al mensaje de otros misioneros (Gal 1,6: "otro evangelio"; Gal 2,7: "el evangelio de la circuncisión"), el término designa el mensaje que Pablo y los demás apóstoles predican (1Cor 15,11). El contenido de dicho mensaje es siempre la buena noticia acerca de Jesucristo; una buena noticia que ellos han recibido y transmiten. Estos rasgos aparecen con claridad en los pasajes en los que Pablo identifica el "evangelio" con las fórmulas de fe tradicionales 18 :

18 Véase: SpalleK, Andrew, "The Origin and Meaning of euaggelion in the Pauline Corpus “, en Concordia Theological Quarterly 57 (1993) 182-187; y STANTON, Jesús y el evangelio, 67-83. 
"Os recuerdo, hermanos, el "evangelio" que os anuncié como buena noticia: Que Cristo murió por nuestros pecados según las Escrituras, que fue sepultado, que resucitó al tercer día según las Escrituras, y que se apareció a Pedro y después a los Doce...” (1Cor 15, 1. 3b-5).

«...el evangelio de Dios, que había anunciado de antemano a sus profetas en las Escrituras santas acerca de su hijo, nacido del linaje de David según la carne, constituido Hijo de Dios con poder según el Espíritu por la resurrección de entre los muertos, Jesús Mesías, nuestro Señor" (Rom 1,1b-4).

En las cartas deuteropaulinas, el término "evangelio" tiene el mismo sentido y el mismo carácter tradicional:

"Acuérdate de Jesús Mesías, resucitado de entre los muertos, de la estirpe de David, según mi evangelio" (2Tim 2,8).

$\mathrm{Y}$ este mismo sentido lo encontramos en las cartas que Ignacio de Antioquía dirige a las comunidades de Asia Menor de camino hacia Roma:

"Pero el evangelio tiene algo de especial: la venida del Salvador, nuestro Señor Jesucristo, su pasión y su resurrección” (Filad 9,2)19.

"Conviene que os apartéis de esas personas y que no habléis de ellas, ni en privado ni en público, y que frecuentéis los profetas y, sobre todo, el evangelio, en el cual se nos muestra la pasión y se cumple la resurrección" (Smir 7,2).

Como la investigación precedente ha señalado de forma unánime, en todos estos escritos de la tradición paulina el "evangelio" es, como en Marcos, la buena noticia acerca de Jesús ${ }^{20}$.

Debido a la importancia que muy pronto adquirió la tradición paulina, esta forma de entender el "evangelio" se difundió enormemente y se convirtió en la visión mayoritaria. Sin embargo, el análisis que hemos realizado más arriba del Evangelio según Mateo pone de manifiesto que esta no era la única forma de entender el sentido del término durante la segunda generación de discípulos. Mateo representa otra trayectoria mucho menos visible en los textos antiguos y también en la investigación

${ }^{19}$ La traducción de los pasajes de Ignacio y de la Didajé toma como referencia el texto griego de a edición de: Kirsopp LaKe (ed.), Apostolic Fathers I (The Loeb Classical Library 24), Harvard University Press, Cambridge, Mass. 1977. Véase también: Filad 5,1; 8,$2 ;$ Smir 5,1-2.

${ }^{20}$ Köster, Ancient Christian Gospels, 4-9. 
reciente, que ha considerado de hecho la tradición paulina como la única relevante 21.

De hecho, el término "evangelio" entendido como buena noticia de Jesús se encuentra en varios textos relacionados entre sí, de modo que también en este caso podemos hablar de una trayectoria. En la Didajé, una instrucción de tipo catequético que es posterior al Evangelio según Mateo, puede leerse:

"No recéis como los hipócritas, sino como el Señor os ha ordenado en el evangelio" (Did 8,2).

"Con respecto a los apóstoles y los profetas actuad según el precepto del evangelio" (Did 11,3).

"Reprendeos los unos a los otros, no con cólera, sino con paz, tal como se prescribe en el evangelio... En vuestras oraciones, vuestras limosnas y todas vuestras acciones, actuad tal como se prescribe en el evangelio de nuestro Señor" (Did 15,3-4).

Estas menciones del término "evangelio" suelen discutirse cuando se trata de aclarar en qué momento dicho término comenzó a designar los evangelios escritos, porque en estos pasajes parece aludirse ya a un texto fijado ${ }^{22}$. Sin embargo, el dato que ahora nos interesa observar es que en estos pasajes el término "evangelio" se refiere, lo mismo que en Mateo, a las enseñanzas de Jesús.

Esta trayectoria en la que se inscriben Mateo y Didajé tiene un antecedente importante en el "Documento Q", la fuente de la que Mateo y Lucas tomaron muchos de los dichos de Jesús que incorporaron a sus respectivos evangelios. Una de las escenas que contenía dicho documento es especialmente significativa en este sentido. Cuando los enviados del Bautista, le preguntan a Jesús si él es el que tenía que venir, este les responde:

"Id a contarle a Juan lo que estáis viendo y oyendo: los ciegos recobran la vista, los tullidos andan derechos, los leprosos son purificados y los sordos oyen, los muertos resucitan, y la buena noticia se anuncia a los pobres" (Mt 11,4-5; par Lc 7,22) 23 .

${ }^{21}$ Un ejemplo elocuente de esta orientación es el magnífico estudio de Stanton que he citado ya varias veces. En la síntesis que hace de él PAHL, Michel, "The 'Gospel' and the 'Word'. Exploring Some Early Christian Patterns", en Journal for the Study of the New Testament 29 (2006) 211-214, se da por supuesto que esta trayectoria era la única y que la visión de Mateo supone una evolución con respecto a Marcos.

22 Ver nota 5.

23 En este caso, la formulación de Mateo y la de Lucas coinciden y, por tanto, no es necesario recurrir aquí a reconstrucción hipotética del texto de Q. En todo caso, véase: 
Aquí Jesús no utiliza el sustantivo "evangelio", pero sí el verbo "evangelizar". En su respuesta, de hecho, combina varias alusiones a textos del profeta Isaías que se refieren a los tiempos mesiánicos (Is 26,19; $29,18 ; 35,5-6)$, añadiendo al final una clara referencia a Is 61,1 , donde se describe la misión del profeta. Esta frase final llama poderosamente la atención, no solo porque rompe la secuencia de la enumeración anterior, que terminaría lógicamente con la resurrección de los muertos, sino también porque interpreta mesiánicamente un texto que en su origen no se refería a los tiempos mesiánicos.

Esta vinculación entre los signos de los tiempos mesiánicos y el anuncio de la buena noticia a los pobres no es, sin embargo, el resultado de un añadido posterior, pues se encuentra ya en un fragmento hallado en Qumrán donde se puede leer una enumeración muy parecida en referencia al Mesías. De él se dice, en efecto, que: "curará a los malheridos, y a los muertos los hará vivir, anunciará buenas noticias a los humildes" (4Q521)24, lo cual revela que Is 61 era interpretado mesiánicamente en tiempos de Jesús 25 . En todo caso, es evidente que en Q el verbo "evangelizar" se refería, como en Mateo y en Didajé, al mensaje anunciado por Jesús.

Así pues, además de la tradición representada por Marcos, en la que el "evangelio" se entendía como la buena noticia sobre Jesús, es posible identificar otra tradición en la que el "evangelio" se entendía como la buena noticia de Jesús ${ }^{26}$. Esto significa que la comprensión mateana del "evangelio" no deriva de Marcos, ni es el reflejo de la nueva situación que vivían sus destinatarios, tal como afirman los estudios redaccionales. Se trata, más bien, de una tradición independiente, que tiene un antecedente en el "Documento Q", y una continuación en la Didajé.

Tenemos así dos trayectorias paralelas. La primera de ellas aparece en una serie de escritos (cartas de Pablo, el Evangelio según Marcos, las cartas deuteropaulinas y las cartas de Ignacio) que pueden localizarse,

Robinson, James, ET AL., The Critical Edition of Q. Synopsis Including the Gospels of Matthew and Luke, Mark and Thomas with English, German, and French Translations of $Q$ and Thomas, Peeters, Leuven 2000, ad locum.

24 Trad.: García Martínez, Florentino, Textos de Qumrán, Trotta, Madrid, 1992, 410; Puech, Emile, "Une apocalypse messianique (4Q521)", en Revue de Qumran 15 (1992) 485-594.

${ }^{25}$ STANTON, Jesús y el evangelio, 35-42. Sobre Is 61 en Q, véase: TUCKETT, Christopher, $Q$ and the History of Early Christianity, Edinburgh, T \& T Clark, 1996, 221-239.

26 A propósito de la relación entre el "Documento Q" y Mateo, LuZ, Ulrich, "Matthew and Q", hace esta interesante observación: "The Tradents of Q and Matthew's community are in historical continuity. This corresponds to the fact that Matthew's version of Q-Matt is relativelly close to the basic material of the Source, and is Jewish Christian in character, as are both Q itself and Matthew's Gospel" (53). 
desde un punto de vista social y geográfico, en la diáspora, pues todos ellos se dirigen a personas que vivían fuera de la tierra de Israel en un contexto vital dominado por la cultura helenística ${ }^{27}$. Sin embargo, los escritos en los que aparece la segunda acepción (el "Documento Q", el Evangelio según Mateo y la Didajé) reflejan un contexto más judío y están vinculados geográficamente a la tierra de Israel28.

La identificación de estas dos acepciones del término "evangelio" evoca un enigmático pasaje de la Carta a los Gálatas, en el que se habla del "evangelio de la incircuncisión" y del "evangelio de la circuncisión" (Gál 2,7)29. Se trata, en efecto, de una afirmación enigmática, porque el mismo Pablo insiste en la misma carta que solo existe un evangelio (Gál 1,7). Este es, de hecho, el único lugar de las cartas en que se habla de dos evangelios que definen dos apostolados: el de Pedro, dirigido a "la circuncisión", y el de Pablo, dirigido a "los gentiles" (Gál 2, 8). Este pasaje es especialmente interesante para nuestro propósito porque, además de distinguir entre dos evangelios, relaciona cada uno de ellos con uno de los contextos culturales que hemos identificado en los textos estudiados.

Ahora bien, a la hora de establecer una relación entre este pasaje y la localización geográfica y social de las dos formas de entender el "evangelio" antes mencionadas, es necesario tener presente que estos dos versículos (Gál 2, 7b-8) poseen una serie de peculiaridades que solo aparecen aquí en las cartas auténticas de Pablo, lo cual ha llevado a algunos a poner en duda su origen paulino ${ }^{30}$. En la investigación reciente se han propuesto dos explicaciones de este hecho: o bien Pablo cita aquí algunos

${ }^{27}$ Las cartas de Pablo, como es sabido, se dirigen a las comunidades fundadas por él en Asia Menor y en las ciudades costeras del Egeo, y a la comunidad de Roma. Las cartas deuteropaulinas y las cartas de Ignacio se dirigen a estas mismas comunidades. Por su parte, el Evangelio de Marcos, aunque fue probablemente compuesto en la región siropalestinense, se dirige a un grupo de comunidades que vivían en un entorno helenístico; véase: FoCANT, L'Évangile, 34-37.

28 Aunque la localización precisa de Q es discutida, todas las hipótesis la sitúan en la región siropalestinense: KlopPENBORG, John, Excavating Q, Fortress Press, Minneapolis 2000. Sobre la relación entre Mateo y Didajé, véase: JEFFORD, Clayton, "The Milieu of Matthew, the Didache an, an Ignatius of Antioch: Agreements and Differences", en VAN DER SANDT, Huub, Matthew and Didache. Two Documents from the same Jewish-Christian Milieu?, Fortress Press, Minneapolis 2005, 39-42, el cual insiste en la diferencia de perspectiva que se aprecia entre estos dos escritos e Ignacio, a pesar de la vinculación de todos ellos con Antioquía. Esta diferencia se debe a que Ignacio no se dirige a las comunidades de Antioquía, sino a las de la diáspora.

29 Agradezco al Prof. Leif E. VAAge la sugerencia de relacionar las dos trayectorias identificadas con esta alusión paulina a dos evangelios.

30 Además de la mención de dos evangelios y de los misiones paralelas, hablan a favor de esta hipótesis el nombre empleado para designar a Pedro (Petros en lugar de 
términos del acuerdo alcanzado en Jerusalén; o bien se trata de una interpolación posterior ${ }^{31}$. En el primer caso, la diferencia reflejaría una distinción establecida en la asamblea de Jerusalén como consecuencia de la doble misión, mientras que en el segundo se trataría de una distinción establecida posteriormente ${ }^{32}$. En cualquiera de los dos casos, sin embargo, se trataría de una referencia no paulina a dos evangelios, que no solo confirma la existencia de dos formas de entender el "evangelio" y su anuncio, sino que las relaciona con contextos geográficos y sociales que coinciden básicamente con los que hemos identificado en el análisis precedente de algunos textos significativos en los que se menciona el término "evangelio" 33 .

\section{IV. “Evangelio” en CONTEXTo}

La distribución geográfica que hemos observado en los escritos antes mencionados no es casual. No se trata solo de dos contextos geográficos, sino de dos contextos sociales diferentes que determinan de forma decisiva la implantación y difusión en ellos del cristianismo naciente. El sustantivo "evangelio" y el verbo "evangelizar" pertenecían al vocabulario de la misión, pues se refieren al mensaje que los primeros discípulos de Jesús anunciaban. Tienen que ver, por tanto, con la difusión e implantación del nuevo grupo religioso formado por ellos.

Ahora bien, en sus inicios, el movimiento de Jesús se difundió en dos contextos sensiblemente diferentes que corresponden a las dos áreas geográficas ya mencionadas: la tierra de Israel y la diáspora. Este es un dato im-

Kephas, que Pablo utiliza siempre) y otras particularidades del vocabulario y el estilo de este pasaje; véase: WALKER, William, "Galatians 2:7b-8 as a Non-Pauline Interpolation", en Catholic Biblical Quarterly 65 (2003) 568-587.

31 Véase: WaLKer, “Galatians 2:7b-8”, 569-574; Lemonon, Jean Pierre, L’Épitre aux Galates (=Commentaire Biblique: Nouveau Testament 9), Cerf, Paris 2008, 89-91; BRUCE, Frederick, The Epistle to the Galatians. A Commentary on the Greek Text, Paternoster, Exeter 1982, 119-121.

32 La tesis de BARnikol, Ernst, "The Non-Pauline Origin of the Parallelism of the Apostles Peter and Paul: Galatians 2:7-8", en Journal of Higher Criticism 44 (1998) 285300 [original alemán 1931], asumida por WALKER, es que la inserción refleja la polémica antimarcionita.

33 Lemonon, L'Épitre aux Galates, 87, hace una descripción de los campos de misión mencionados en Gál 2, 8 y 2, 9 que coincide con la que más arriba hemos identificado, subrayando que se trata de una distribución desigual, pues Pedro y las columnas se habrían reservado la región siropalestinense y las zonas de la diáspora donde el judaísmo estaba más presente, mientras que a Pablo y los suyos les habrían correspondido las regiones donde el judaísmo era minoritario o estaba del todo ausente. 
portante para comprender por qué existe una diferencia regional tan acusada en la comprensión de unos términos tan importantes. Las ciencias sociales, que han estudiado los procesos de difusión e implantación de nuevos movimientos religiosos nos ofrecen algunas claves para comprender este fenómeno. Antes de recurrir a ellas, sin embargo, quisiera precisar los dos términos que he utilizado antes para designar ambos contextos.

El término "diáspora" que he utilizado para referirme al contexto en el que hay que situar los textos de la tradición paulina, incluye solo una parte de la compleja realidad que designa esta palabra. Había otra diáspora al oriente de la tierra de Israel, y también otras ciudades en la diáspora occidental que tenían importantes colonias judías. En las ciudades a las que se dirigen los escritos de la tradición paulina, sin embargo, la presencia judía era mucho más discreta y, en algunos casos, insignificante. Por su parte, la tierra de Israel, que era la patria de origen del movimiento cristiano, no solo incluye los territorios de Palestina, sino que se extiende hacia el norte hasta la ciudad de Antioquía, formando lo que Martin Hengel ha llamado la "Gran Judea"34. En este territorio había una importante presencia de la cultura helenística, pero lo que define a esta región desde el punto de vista religioso y cultural es la fuerte implantación que tenía en ella el judaísmo.

Así pues, la principal diferencia entre estos dos contextos, desde el punto de vista religioso, era la implantación en ellos del judaísmo, pues mientras en la tierra de Israel los diversos grupos judíos tenían una implantación muy notable y ejercían un influjo determinante, en la diáspora esta implantación era mucho menor y su influjo no era tan determinante.

La sociología de la religión ha elaborado una tipología que ayuda a comprender cómo estas dos situaciones determinan la difusión de un nuevo movimiento religioso ${ }^{35}$. En sus inicios, los nuevos movimientos religiosos suelen adoptar dos formas. En algunos casos, surgen como movimientos de renovación que se escinden de otros grupos religiosos ya existentes dentro de un contexto en que el grupo de origen sigue existiendo. En otros casos, sin embargo, comienzan como movimientos nuevos, sea porque no se han originado a partir de otro grupo religioso, o porque éste no tiene una presencia significativa en el nuevo contexto.

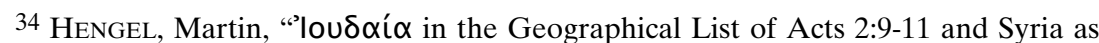
'Greater Judea”, en Bulletin for Biblical Research 10 (2000) 161-180.

35 Retomo en estos párrafos algunas de las reflexiones ya formuladas en GUIJARRO Oporto, Santiago, "El Jesús de Pablo. Una aportación desde las ciencias sociales", en Salmanticensis 57 (2010) 415-435, 424-429. 
La sociología de la religión llama a los primeros "sectas" y a los segundos "cultos". Desde el punto de vista sociológico, una secta puede definirse como "un movimiento separatista de renovación, que surge dentro de un sistema establecido y religiosamente definido con el que comparte una visión simbólica del mundo". Por su parte, un culto "es un movimiento integrador, a menudo sincretista, que se importa eficazmente a otro sistema cultural religiosamente definido, con el que trata de sintetizar su novedosa visión simbólica del mundo" 36 .

Los grupos de discípulos de Jesús que fueron surgiendo en la región siropalestinense encajan en la tipología de la secta, pues se habían escindido de otro grupo religioso, cuya visión del mundo compartían, para proponer una profunda renovación del mismo a partir de su adhesión a Jesús ${ }^{37}$. Ahora bien, la principal preocupación de un movimiento religioso que se ha separado de otro con la intención de proponer una vivencia más radical o nueva, es definir y afirmar su propia identidad frente al grupo de origen. Por esa razón, los grupos que surgen en esta situación desarrollan estrategias de diferenciación y de autoafirmación con respecto a la religión de origen.

Por su parte, los grupos de discípulos nacidos en la diáspora tienen las características propias de un culto. El grupo religioso del que se habían escindido, es decir, el Judaísmo, no era mayoritario en su entorno. El panorama religioso del mundo en el que vivían era, de hecho, bastante plural, pues junto a las religiones tradicionales de cada región, que seguían siendo practicadas, en época relativamente reciente se habían implantado diversos cultos extranjeros de carácter mistérico y se había difundido el culto al emperador, que fue adquiriendo una importancia cada vez mayor ${ }^{38}$. En este contexto, el reto que se presentaba a las comu-

36 Tomo estas definiciones de White, Michel, De Jesús al cristianismo, Verbo Divino, Estella 2004, 170, quien ha aplicado esta terminología a los primeros grupos cristianos en un trabajo más extenso: WHITE, Michel, "Shifting Sectarian Boundaries in Early Christianity", en Bulletin of the John Rylands Library 70 (1988) 7-24. Esta distinción fue propuesta por STARK, Rodney - Sims BAINBRIDGE, William, "Of Churches, Sects, and Cults: Preliminary Concepts for a Theory of Religious Movements" en Journal for the Scientific Study of Religion 18 (1979) 117-131; véanse especialmente pp. 124-126. Estos dos autores desarrollaron más tarde su visión de estas dos formas de movimiento religioso en: STARK, Rodney - Sims Bainbridge, William, A Theory of Religion, Rutgers University Press, New Brumswick² 1996, 121-193.

${ }^{37}$ El surgimiento de este tipo de grupos es un fenómeno característico del judaísmo del segundo templo, como ha mostrado BAumgarten, Albert, The Flourishing of Jewish Sects in the Maccabean Era, Brill, Leiden 1997.

38 Una síntesis de la situación religiosa del mundo grecorromano puede verse en: Klauck, Hans, The Religious Context of Early Christianity. A Guide to Graeco-Roman Religions, Fortress Press, Minneapolis 2000. 
nidades cristianas no era la diferenciación con respecto al judaísmo, sino la asimilación al nuevo entorno.

Esta distinción es muy importante para comprender las estrategias que estos grupos desarrollaron respecto a la tradición sobre Jesús. Los que estaban asentados en la región siropalestinense, cuya principal preocupación era distinguirse del judaísmo mayoritario, tuvieron gran interés en conservar y transmitir las tradiciones sobre el Jesús terreno, sobre todo los dichos y anécdotas en los que aparecía como un maestro que había propuesto una nueva forma de interpretar y de vivir el judaísmo. Por esta razón, fue sobre todo en la región siropalestinense donde se conservó y se transmitió la tradición sobre Jesús que más tarde quedaría recogida en los evangelios. Esto explica que para ellos el "evangelio" fuera, ante todo, la buena noticia anunciada por Jesús.

Por su parte, los grupos de discípulos de la diáspora se afanaron por ser aceptados en un entorno religioso plural. Su estrategia fue, por tanto, la asimilación. Si querían que el mensaje que anunciaban fuera relevante para sus destinatarios, debían presentarse como una de las religiones que ellos conocían ${ }^{39}$. Estas, a pesar de sus diferencias, compartían una concepción de la divinidad menos rígida que la del estricto monoteísmo judío. Los héroes eran fácilmente divinizados, lo mismo que los emperadores, y se aceptaban con agrado las divinidades y los cultos extranjeros. Por esta razón, en las cartas de Pablo, que reflejan este contexto, las noticias sobre el Jesús terreno son muy escasas, mientras que las afirmaciones sobre el Jesús glorificado son muy abundantes. Este explica que para estos grupos el "evangelio" fuera, ante todo, la buena noticia sobre Jesús.

Así pues, la diferencia que hemos observado inicialmente en los Evangelios según Marcos y según Mateo, y más tarde en otros escritos, en cuanto a la forma de entender el término "evangelio", así como el hecho de que ambas acepciones del término coexistieran dentro del naciente movimiento cristiano, puede explicarse, en parte, por los contextos en los que se utilizó esta palabra fundamental del sociolecto cristiano. Este hecho tiene un significado teológico que quisiera comentar brevemente como conclusión de este estudio.

39 Este proceso de asimilación al entorno continuó de forma muy visible durante la segunda generación en el ámbito de las comunidades paulinas; véase: GUIJARRo OPORTO, Santiago, "Cristianos en el mundo. Las comunidades cristianas de la segunda generación en la sociedad helenístico-romana", en Salmanticensis 48 (2001) 5-39. 


\section{El "EVANGELIO" COMPLETo}

La principal conclusión de este estudio es que el término "evangelio", una de las palabras claves del vocabulario elaborado por los primeros cristianos para definir su nueva identidad, fue entendido de forma diferente por los diversos grupos de discípulos de Jesús. Según el modelo evolucionista de la crítica redaccional, estos diversos sentidos corresponderían a dos momentos sucesivos: el del anuncio prepascual de Jesús, cuyo contenido era la llegada del reinado de Dios, y el del anuncio postpascual de sus discípulos, cuyo contenido sería el kerygma de su muerte y resurrección. Este modelo, sin embargo, no es capaz de explicar el hecho de que, incluso después de la Pascua las dos acepciones del término "evangelio" hayan coexistido.

La constatación de que la visión mateana del "evangelio" no es un desarrollo de la que su autor encontró en el relato de Marcos, sino más bien el reflejo de una comprensión genuina del término, que enlaza con una tradición anterior atestiguada en las tradiciones recogidas en el "Documento Q", y con un desarrollo posterior atestiguado en la Didaché, ha puesto de manifiesto la existencia de una trayectoria paralela a la que representan los escritos de la tradición paulina. El evangelio sobre Jesús y el evangelio de Jesús coexistieron en una tensión creativa en los comienzos del cristianismo.

Este "mestizaje de sentidos" revela dos rasgos muy característicos del cristianismo naciente. Por un lado, su disposición para dialogar con los contextos en los que se integró, y por otro su capacidad para mantener, a pesar de las tensiones que ello provoca, una pluralidad inclusiva. El primer rasgo se percibe en actitudes fundamentales como la aceptación y transformación de las estructuras sociales, principalmente la casa, mientras que el segundo tiene su mejor expresión en la diversidad de los escritos que incorporó al canon de sus Escrituras. En el caso que nos ocupa, la disposición para dialogar con los diversos contextos dio como resultado dos formas de entender el término evangelio que eran significativas para los diversos destinatarios. Por su parte, la capacidad para mantener esta pluralidad inclusiva, hizo que no se perdieran los matices que ambas formas de entender el "evangelio" subrayaban.

Ahora bien, el hecho de que estas dos formas de entender el "evangelio" hayan coexistido entre los primeros grupos de discípulos de Jesús, y sigan coexistiendo en el canon, tiene un profundo significado. No se trata solo de un dato histórico, sino que es también un dato teológico que 
previene contra cualquier comprensión sesgada o parcial del evangelio. Lo que el dato teológico subraya es que el evangelio sobre Jesús y el evangelio de Jesús son complementarios, y que, por tanto, no se puede anunciar el uno sin el otro. El evangelio sobre Jesús, es decir el anuncio gozoso de que él es el Hijo de Dios encarnado, que murió y resucitó por nosotros y que participa de la gloria del Padre, no está completo sin el evangelio de Jesús, es decir, sin el anuncio de la inminente llegada del reinado de Dios que transformará este mundo. Del mismo modo, tampoco el evangelio de Jesús está completo sin el evangelio sobre Jesús. La tentación de un evangelio parcial, en un sentido o en otro, está presente en la iglesia desde sus orígenes. Por eso, el hecho de que en los escritos del Nuevo Testamento haya quedado memoria de esta pluralidad inclusiva de los diversos sentidos del término "evangelio" es, sin duda, una advertencia saludable que invita a buscar, más allá de las preferencias y sensibilidades personales o de grupo, el evangelio completo. 